\title{
Synthesis, experimental and theoretical vibrational studies of 1-methyl and 1,2-dimethyl, 3-propyl imidazolium bis(trifluoromethanesulfonyl) imide
}

\author{
M DRAI $^{\mathrm{a}, \mathrm{b}}$, A MOSTEFAI $^{\mathrm{c}}$, A PAOLONE $^{\mathrm{d}, *}$ (1), B HADDAD $^{\mathrm{b}, \mathrm{c}, \mathrm{e}}, \mathrm{E} \mathrm{BELARBI}^{\mathrm{b}}$,

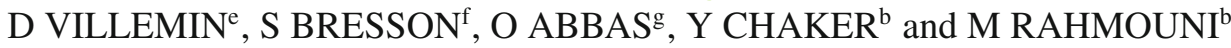 \\ ${ }^{a}$ Laboratoire de Matériaux \& Catalyse, Université Djillali Liabès, BP 89, 22000 Sidi-Bel-Abbès, Algeria \\ ${ }^{\mathrm{b}}$ Synthesis and Catalysis Laboratory LSCT, Tiaret University, Tiaret, Algeria \\ ${ }^{\mathrm{c}}$ Department of Chemistry, Dr Moulay Tahar University of Saida, Saida, Algeria \\ ${ }^{\mathrm{d}}$ CNR-ISC, U.O.S. La Sapienza, Piazzale A Moro 5, 00185 Rome, Italy \\ ${ }^{e}$ LCMT, ENSICAEN, UMR 6507 CNRS, University of Caen, 6 bd Ml Juin, 14050 Caen, France \\ ${ }_{\mathrm{f}}^{\mathrm{L}}$ aboratoire de Physique des Systèmes Complexes, Université Picardie Jules Verne, 33 rue St Leu, \\ 80039 Amiens Cedex, France \\ ${ }^{g}$ Centre Wallon de Recherche Agronomique, CRA-W, Bâtiment Maurice Henseval, Chaussée de Namur, 24, \\ 50030 Gembloux, Belgium \\ E-mail: Annalisa.Paolone@roma1.infn.it
}

MS received 2 December 2016; accepted 10 April 2017

\begin{abstract}
In this study, two ionic liquids containing the bis(trifluoromethanesulfonyl)imide $\left(\left[\left(\mathrm{CF}_{3} \mathrm{SO}_{2}\right)_{2} \mathrm{~N}^{-}\right]\right)$ anion are synthesized. The syntheses are based on an alkylation reaction of 1-methyl imidazole and 1,2-dimethyl imidazole followed by anion exchange. The obtained ILs are characterized by ${ }^{1} \mathrm{H}-\mathrm{NMR},{ }^{13} \mathrm{C}-\mathrm{NMR},{ }^{19} \mathrm{~F}-\mathrm{NMR}$ and FT-IR spectroscopy. Vibrational spectroscopy studies were conducted by infrared (FTIR/ATR), Raman spectroscopy and DFT calculations. The presence of methylation in the $\mathrm{C} 2$ position gives rise to specific marker bands in the Raman and IR spectra. In order to ascertain whether cation conformers are present in our ionic liquids, a computational study was performed using the density functional theory. The comparison of the experimental data and the computed spectra shows that three conformers of the imidazolium ions are present in both ionic liquids.
\end{abstract}

Keywords. Ionic liquids ILs; FT-Raman; FT IR/ATR; imidazolium; density functional theory; conformers.

\section{Introduction}

In the past few decades, new compounds, named ionic liquids, have displayed improved thermal, chemical and electrochemical properties in comparison with the volatile organic compounds (VOCs) ${ }^{1}$. Because of their interesting properties, they have been considered for promising applications in various fields such as electrochemistry ${ }^{2}$ inorganic chemistry, ${ }^{3}$ catalysis, ${ }^{4}$ engineering, ${ }^{5}$ spectroscopy ${ }^{6-8}$ and material science. ${ }^{9}$ For these reasons, the physicochemical properties of ionic liquids have been largely investigated. ${ }^{8}$

The properties of ionic liquids are generally influenced by the nature of cations and anions. Among these compounds, ionic liquids (ILs) based on the bis(trifluoromethanesulfonyl) imide $\left[\left(\mathrm{CF}_{3} \mathrm{SO}_{2}\right)_{2} \mathrm{~N}^{-}\right]$ anion represent a new generation of ILs; they have special properties that make them very attractive, ${ }^{10}$ such

\footnotetext{
*For correspondence
}

as their high ionic conductivity, low melting points and low viscosity compared to other ILs. ${ }^{11}$ For these reasons they are expected to have several application opportunities in the field of lithium batteries. ${ }^{12}$

Recently, many studies investigated the spectroscopic properties of ionic liquids; ${ }^{13-18}$ generally, the aim of these works is to elucidate the relationship between the structures of ILs and their physicochemical properties; that is to say, a better comprehensive interpretation of the spectroscopic properties can be reached if physicochemical investigations are correlated with structural ones.

In this framework, detailed spectroscopic studies indicate that replacing hydrogen by a methyl group at $\mathrm{C} 2$ position in the imidazolium ring leads to a very significant variation of the macroscopic properties. Therefore, the comprehension of a relationship between macroscopic properties (i.e., melting point, viscosity, conductivity, etc.) and structural properties is 
essential for designing ILs with desirable properties. In this regard, several studies have been reported in the literature. For example, Bonhote et al. ${ }^{19}$ and others $^{20-26}$ found that methylation of the $\mathrm{C}(2)$ position of 1,3-dialkylimidazolium based ionic liquids disrupts the predominant hydrogen bonding interaction between cation and anion leading to unexpected changes of the physicochemical properties. For example, to reveal the impact of extra methyl substitution at the $\mathrm{C} 2$ position and getting information on their effect on the properties of imidazolium ionic liquids, Chen et al.,${ }^{27}$ found the viscosity of cationic C2-methylated 1,2-dimethy 1,3-propyl imidazolium bis(trifluoromethane-sulfonyl) imide $(\eta=88.9 \mathrm{cP})$ to be about twice higher than that of their cationic C2-protonated 1-methyl,3-propyl imidazolium bis(trifluoromethane sulfonyl) imide $(\eta=43.7$ $\mathrm{cP}$ ) at $\mathrm{T}=25^{\circ} \mathrm{C}$. In the same way, many studies were devoted to the spectroscopic properties of various ionic liquids by using DFT calculations and ab initio MD simulations in order to investigate the hydrogen bonding between cation and anion in these compounds. ${ }^{28-32}$

Inspired by the previous research, the present work focuses on the synthesis and vibrational properties of two ionic liquids, namely: 1-methyl,3-propyl imidazolium bis(trifluoromethane-sulfonyl) imide $\left(\left[1-\mathrm{MPrIM}{ }^{+}\right]\left[\left(\mathrm{CF}_{3} \mathrm{SO}_{2}\right)_{2} \mathrm{~N}^{-}\right]\right)$and 1,2-dimethyl,3propyl imidazolium bis(trifluoromethane-sulfonyl) imide ([1, 2-DMPrIM $\left.\left.{ }^{+}\right]\left[\left(\mathrm{CF}_{3} \mathrm{SO}_{2}\right)_{2} \mathrm{~N}^{-}\right]\right)$. The understanding of the vibrational structures is important to explain the influence of the methyl group at $\mathrm{C} 2$ position (effect of methylation) between the two synthesized ILs. For this purpose, experimental and computational study of both [1-MPrIM $\left.{ }^{+}\right]\left[\left(\mathrm{CF}_{3} \mathrm{SO}_{2}\right)_{2} \mathrm{~N}^{-}\right]$and $\left[1,2-\mathrm{DMPrIM}^{+}\right]\left[\left(\mathrm{CF}_{3} \mathrm{SO}_{2}\right)_{2} \mathrm{~N}^{-}\right]$were performed using the infrared (FTIR/ATR) and Raman spectroscopy and DFT calculations.

\section{Experimental}

\subsection{Materials, synthesis and preliminary characterization}

The reagents used in this study are: 1-methylimidazole (> 99\%), 1,2-dimethylimidazole (98\%), propyl iodide (98\%), lithium bis(trifluoromethylsulfonyl) Imide (99\%). They were purchased from Fluka and used as received. Deionized $\mathrm{H}_{2} \mathrm{O}$ was obtained with a Millipore ion-exchange resin deionizer.

${ }^{1} \mathrm{H}$ NMR $(400 \mathrm{MHz})$ and ${ }^{13} \mathrm{C}$ NMR spectra were recorded on a DRX $400 \mathrm{MHz}$ spectrometer. The chemical shifts $(\delta)$ are given in ppm and referred to the internal solvent signal, namely, tetramethylsilane (TMS) and trichlorofluoromethane $\left(\mathrm{CFCl}_{3}\right)$. Preliminary IR spectra were recorded on a FT-IR Perkin-Elmer BX spectrophotometer with a resolution of $4 \mathrm{~cm}^{-1}$ in the range $4000-650 \mathrm{~cm}^{-1}$ in order to check the occurrence of the expected chemical reactions and the production of the ionic liquids.

\subsection{General procedure for the synthesis of two ILs}

1-methyl-3-propylimidazolium bis(trifluoromethanesulfonyl) imide $\left[1-\mathrm{MPrIM}^{+}\right]\left[\left(\mathrm{CF}_{3} \mathrm{SO}_{2}\right)_{2} \mathrm{~N}^{-}\right]$and 1,2dimethyl, 3-propyl imidazolium bis(trifluoromethanesulfonyl) imide [1, 2-DMPrIM $\left.{ }^{+}\right]\left[\left(\mathrm{CF}_{3} \mathrm{SO}_{2}\right)_{2} \mathrm{~N}^{-}\right]$were synthesized following the procedures described in the literature. ${ }^{33}$ Briefly, the chemical reaction of 1-methylimidazole and 1,2-dimethylimidazole with propyl iodide results in transfer of the propyl group to the imidazolium ring and results in 1-methyl,3-propyl imidazolium and 1,2-dimethyl,3propyl imidazolium combined with iodide anion, respectively. Both iodide ILs were subjected to anion exchange from iodide to bis(trifluoromethane-sulfonyl) imide. The reaction of lithium bis(trifluoromethanesulfonyl) imide with these two iodide ILs in water leads to the corresponding ionic liquids, $\left[1-\mathrm{MPrIM}^{+}\right]\left[\left(\mathrm{CF}_{3} \mathrm{SO}_{2}\right)_{2} \mathrm{~N}^{-}\right]$and $\left[1,2-\mathrm{DMPrIM}^{+}\right]$ $\left[\left(\mathrm{CF}_{3} \mathrm{SO}_{2}\right)_{2} \mathrm{~N}^{-}\right]$. The resulting 1-methyl,3-propyl imidazolium bis(trifluoromethane-sulfonyl) imide and 1,2dimethyl,3-propyl imidazolium bis(trifluoromethane-sulfonyl) imide were obtained as yellowish viscous liquids. Scheme 1 shows the general synthesis of $\left[1-\mathrm{MPrIM}^{+}\right]\left[\left(\mathrm{CF}_{3} \mathrm{SO}_{2}\right)_{2} \mathrm{~N}^{-}\right]$ and $\left[1,2-\mathrm{DMPrIM}^{+}\right]\left[\left(\mathrm{CF}_{3} \mathrm{SO}_{2}\right)_{2} \mathrm{~N}^{-}\right]$.

To confirm the absence of any major impurity in the two investigated ILs, their structures were ascertained using ${ }^{1} \mathrm{H}$, ${ }^{13} \mathrm{C},{ }^{19} \mathrm{~F}-\mathrm{NMR}$ and FT-IR spectroscopy. The spectroscopic data are given below and the ${ }^{1} \mathrm{H},{ }^{13} \mathrm{C}$ and ${ }^{19} \mathrm{~F}$-NMR spectra are presented in Figures S1 and S2 (see Supplementary Information).

2.2a $\left[1-M \operatorname{PrIM} M^{+}\right]\left[\left(\mathrm{CF}_{3} \mathrm{SO}_{2}\right)_{2} \mathrm{~N}^{-}\right]: \quad{ }^{1} \mathrm{H} \mathrm{NMR}$ (DMSO, $400 \mathrm{MHz}) \delta: 9.75(1 \mathrm{H}, \mathrm{s}), 7.55(1 \mathrm{H}, \mathrm{s}), 7.52(1 \mathrm{H}$, s), $4.17-4.21(2 \mathrm{H}, \mathrm{t}, J=8 \mathrm{~Hz}), 3.99(3 \mathrm{H}, \mathrm{s}), 1.82-1.87(2 \mathrm{H}$, $\mathrm{m}, J=8 \mathrm{~Hz}), 0.83-0.87(3 \mathrm{H}, \mathrm{t}, J=8 \mathrm{~Hz}) ;{ }^{13} \mathrm{C} \mathrm{NMR}$ $\left(\mathrm{CDCl}_{3}, 100.6 \mathrm{MHz}\right) \delta: 10.4,11.6,22.6,49.9,120.8,122.2$, $122.2,144.2 ;{ }^{19} \mathrm{~F} \mathrm{NMR}\left(\mathrm{CDCl}_{3}, 100.6 \mathrm{MHz}\right) \delta:-79.0(\mathrm{~s}$, $\left.\left.\mathrm{CF}_{3} \mathrm{SO}_{2}\right)_{2} \mathrm{~N}-\right)$. IR $\left(\tilde{v} / \mathrm{cm}^{-1}\right): 3123$ [v (=C-H)], 2978, 2887 $[v(\mathrm{C}-\mathrm{H})], 1461[\delta(\mathrm{C}-\mathrm{H})], 1347,1329[v(\mathrm{~S}=\mathrm{O})], 1179[v(\mathrm{C}-$ $\mathrm{F})], 1132[\delta(\mathrm{S}=\mathrm{O})], 1051[\delta(\mathrm{C}-\mathrm{F})]$.

2.2b $\left[1,2-D M \operatorname{PrIM} M^{+}\right]\left[\left(\mathrm{CF}_{3} \mathrm{SO}_{2}\right)_{2} \mathrm{~N}^{-}\right]:{ }^{1} \mathrm{H} \mathrm{NMR}$ $\left(\mathrm{CDCl}_{3}, 400 \mathrm{MHz}\right) \delta: 7.32(1 \mathrm{H}, \mathrm{d}), 7.24(1 \mathrm{H}, \mathrm{d}), 3.85-3.89$ $(2 \mathrm{H}, \mathrm{q}, J=8 \mathrm{~Hz}), 3.67(3 \mathrm{H}, \mathrm{s}), 2.50(3 \mathrm{H}, \mathrm{s}), 1.54-1.59$ $(2 \mathrm{H}, \mathrm{m}, J=4 \mathrm{~Hz}), 0.66-0.69(3 \mathrm{H}, \mathrm{t}, J=8 \mathrm{~Hz}) ;{ }^{13} \mathrm{C} \mathrm{NMR}$ $\left(\mathrm{CDCl}_{3}, 100.6 \mathrm{MHz}\right) \delta: 9.4,10.5,14.8,36.3,50.0,120.9$, $122.3,122.4,143,2-143.3 ;{ }^{19} \mathrm{~F} \mathrm{NMR}\left(\mathrm{CDCl}_{3}, 100.6 \mathrm{MHz}\right)$ $\left.\delta:-78.82\left(\mathrm{~s}, \mathrm{CF}_{3} \mathrm{SO}_{2}\right)_{2} \mathrm{~N}-\right)$. IR $\left(\tilde{v} / \mathrm{cm}^{-1}\right): 3152[v(=\mathrm{C}-\mathrm{H})]$, 2974, $2885[v(\mathrm{C}-\mathrm{H})], 1540,1462[\delta(\mathrm{C}-\mathrm{H})], 1347,1329[v$ $(\mathrm{S}=\mathrm{O})], 1176[v(\mathrm{C}-\mathrm{F})], 1132[\delta(\mathrm{S}=\mathrm{O})], 1054$ [ $\delta(\mathrm{C}-\mathrm{F})]$.

\subsection{FTIR/ATR and FT-RAMAN measurements}

The Infrared ATR spectra and Raman spectra, reported in the following Sections 3.1 and 3.2, were performed in the 

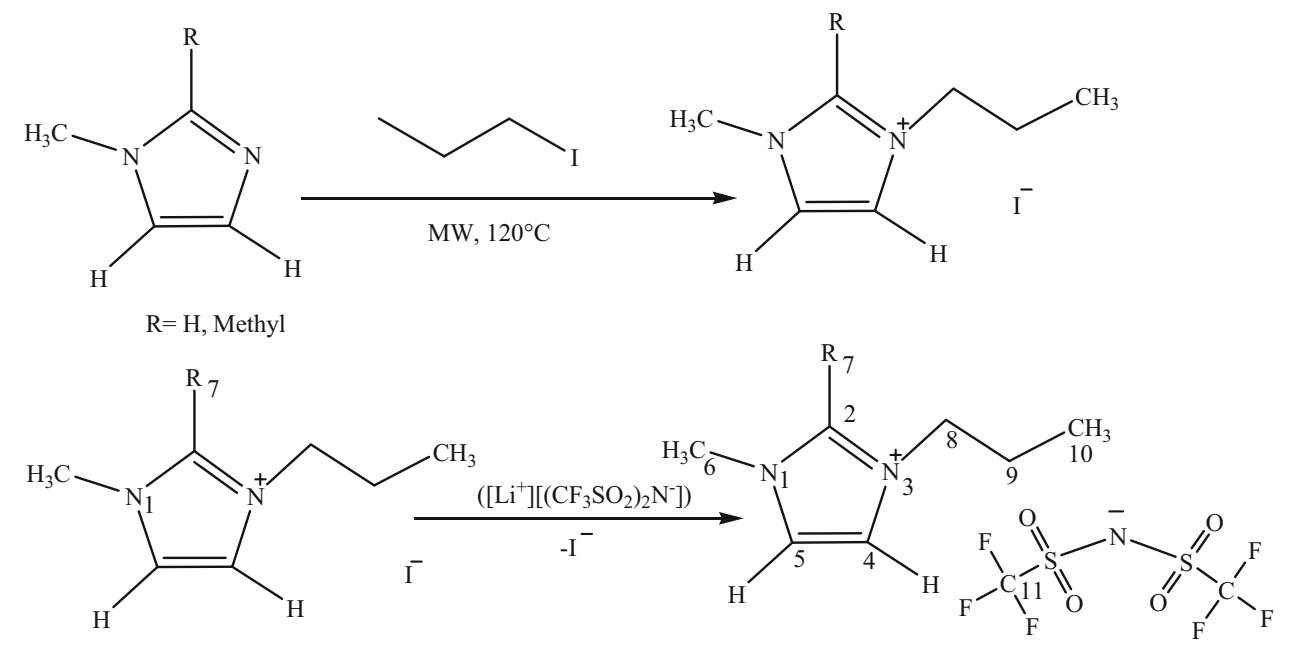

Scheme 1. General synthesis of ionic liquids, $\left[1-\mathrm{MPrIM}^{+}\right]\left[\left(\mathrm{CF}_{3} \mathrm{SO}_{2}\right)_{2} \mathrm{~N}^{-}\right]$and $\left[1,2-\mathrm{DMPrIM}^{+}\right]\left[\left(\mathrm{CF}_{3} \mathrm{SO}_{2}\right)_{2} \mathrm{~N}^{-}\right] . \mathrm{MW}=$ microwave.

Walloon Agricultural Research Center (Craw) Belgium. For both kind of measurements the as-synthesized samples were used without further purification.

The FTIR/Attenuated Total Reflectance (FTIR/ATR) measurements were acquired on a Bruker Vertex II-70RAM Spectrometer (Bruker Analytical, Madison, WI) operating with a Golden Gate diamond ATR accessory TM (Specac Ltd, Slough, uk). A drop of the synthesized ionic liquids was placed directly on the ATR crystal. The FTIR/ATR spectra [600-4000 $\mathrm{cm}^{-1}$ ] were collected with $1 \mathrm{~cm}^{-1}$ nominal resolution by co-adding 64 scans for each spectrum. The OPUS Software 6.0 for Windows was used for the management of the instrument.

FT-RAMAN spectra were acquired on a Vertex 70-RAM II Bruker FT-Raman spectrometer. This instrument is equipped with a Nd:YAG laser (yttrium aluminium garnet crystal doped with triply ionized neodymium) with a wavelength of 1064 $\mathrm{nm}$ and a maximum power of $1.5 \mathrm{~W}$. The measurement accessory is pre-aligned: only the Z-axis of the scattered light is adjusted to set the sample in the appropriate position regarding the local measurement point. The RAM II spectrometer is equipped with a liquid nitrogen cooled Ge detector. A drop of the as-synthesized samples was placed in a quartz cell and maximization of the Raman scattered light was performed. FT-Raman spectra [45-4000 $\mathrm{cm}^{-1}$ ] were collected with $1 \mathrm{~cm}^{-1}$ resolution by co-adding 128 scans for each spectrum at room temperature. The OPUS 6.0 software was used for the spectral acquisition, manipulation and transformation.

\section{Results and discussion}

\subsection{IR spectroscopy}

The FTIR/ATR [600-3400 $\mathrm{cm}^{-1}$ ] spectra of the two investigated ILs, namely, [1-MPrIM $\left.{ }^{+}\right]\left[\left(\mathrm{CF}_{3} \mathrm{SO}_{2}\right)_{2} \mathrm{~N}^{-}\right]$ and $\left[1,2-\mathrm{DMPrIM}^{+}\right]\left[\left(\mathrm{CF}_{3} \mathrm{SO}_{2}\right)_{2} \mathrm{~N}^{-}\right]$are shown in
Figures 1 and 2, divided in two spectral regions: 600$1700 \mathrm{~cm}^{-1}$ and $2800-3400 \mathrm{~cm}^{-1}$.

3.1a The 600-1700 $\mathrm{cm}^{-1}$ region: The spectra of the two ILs look similar. However, two peaks observed in this region are important indication for the methylation effect in $\mathrm{C} 2$ position. A first difference between the spectra of methylated [1, 2-DMPrIM $\left.{ }^{+}\right]\left[\left(\mathrm{CF}_{3} \mathrm{SO}_{2}\right)_{2} \mathrm{~N}^{-}\right]$and non-methylated $\left[1 \mathrm{MPrIM}^{+}\right]\left[\left(\mathrm{CF}_{3} \mathrm{SO}_{2}\right)_{2} \mathrm{~N}^{-}\right]$ILs occurs at $844 \mathrm{~cm}^{-1}$; this band is assigned to $\mathrm{CH}$ bending vibration in the ring $\mathrm{NC}(\mathrm{H}) \mathrm{N}$. The absence of this mode in the methylated [1, 2-DMPrIM $\left.{ }^{+}\right]\left[\left(\mathrm{CF}_{3} \mathrm{SO}_{2}\right)_{2} \mathrm{~N}^{-}\right]$supports this assignment (this band is observed at $846 \mathrm{~cm}^{-1}$ in the study by Noack et $a l .{ }^{24}$ ).

Furthermore, the presence of a characteristic band at $1540 \mathrm{~cm}^{-1}$ in $\left[1,2-\mathrm{DMPrIM}^{+}\right]\left[\left(\mathrm{CF}_{3} \mathrm{SO}_{2}\right)_{2} \mathrm{~N}^{-}\right]$and at $1571 \mathrm{~cm}^{-1}$ in $\left[1-\mathrm{MPrIM}^{+}\right]\left[\left(\mathrm{CF}_{3} \mathrm{SO}_{2}\right)_{2} \mathrm{~N}^{-}\right]$, can be attributed to a $\mathrm{CC}$ stretching in $\mathrm{NC}\left(\mathrm{CH}_{3}\right) \mathrm{N}$ ring and $\mathrm{NC}_{2}(\mathrm{H}) \mathrm{N}$ ring; here, again the methylation effect is clearly observed. These vibrational mode assignment agrees also with that proposed by Noack et al., who also found that there is a broad peak around $1540 \mathrm{~cm}^{-1}$ assigned to $\mathrm{CC}$ stretching in $\mathrm{NC}\left(\mathrm{CH}_{3}\right) \mathrm{N}$ ring. ${ }^{24}$

As indicated in Table 1, all bands in the FTIR/ATR spectra appearing in this region can be mainly ascribed to contributions from ring bending modes of the imidazolium cation and to modes of $\left.\left[\left(\mathrm{CF}_{3} \mathrm{SO}_{2}\right)_{2} \mathrm{~N}^{-}\right]\right)$anion. For example, the most intense IR bands at 1051, 1132, $1174,1226,1330,1346$ and $1446 \mathrm{~cm}^{-1}$ are common in both ILs, as they are dominated by vibrations of the $\left.\left[\left(\mathrm{CF}_{3} \mathrm{SO}_{2}\right)_{2} \mathrm{~N}^{-}\right]\right)$anion. ${ }^{34-39}$

3.1b The 2800-3400 $\mathrm{cm}^{-1}$ region: In this region, the same absorption bands can be observed in the 


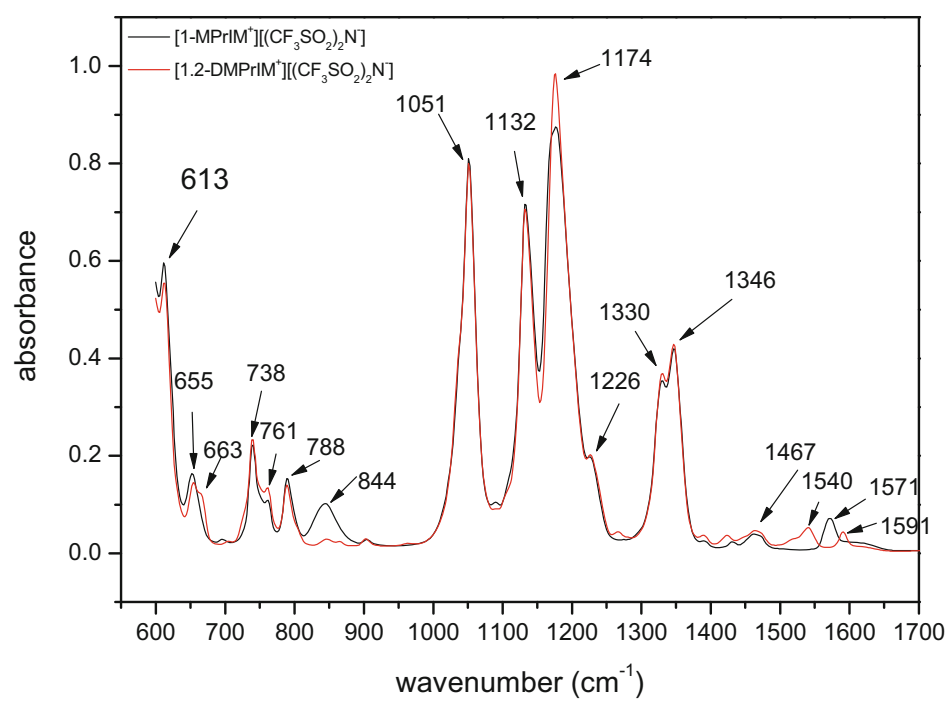

Figure 1. FTIR/ATR spectra of $\left[1-\mathrm{MPrIM}^{+}\right]\left[\left(\mathrm{CF}_{3} \mathrm{SO}_{2}\right)_{2} \mathrm{~N}^{-}\right]$and $\left[1,2-\mathrm{DMPrIM}^{+}\right]\left[\left(\mathrm{CF}_{3} \mathrm{SO}_{2}\right)_{2} \mathrm{~N}^{-}\right]$in the spectral range $550-1700$ $\mathrm{cm}^{-1}$.

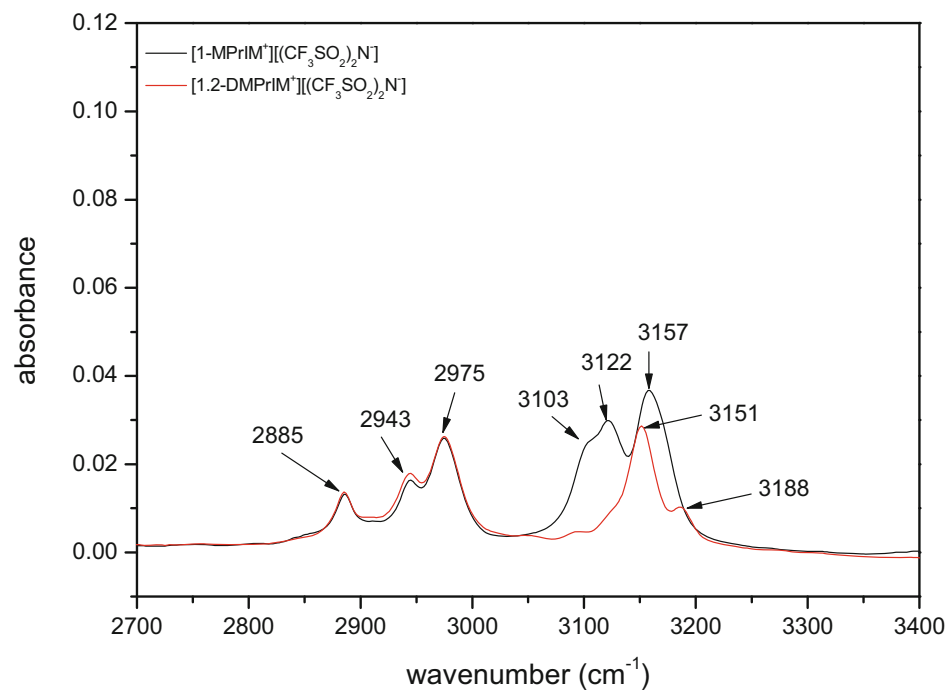

Figure 2. FTIR/ATR spectra of $\left[1-\mathrm{MPrIM}^{+}\right]\left[\left(\mathrm{CF}_{3} \mathrm{SO}_{2}\right)_{2} \mathrm{~N}^{-}\right]$and $\left[1,2-\mathrm{DMPrIM}^{+}\right]\left[\left(\mathrm{CF}_{3} \mathrm{SO}_{2}\right)_{2} \mathrm{~N}^{-}\right]$in the spectral range $2800-3400$ $\mathrm{cm}^{-1}$.

FTIR/ATR spectra of the two ILs below $3000 \mathrm{~cm}^{-1}$. The bands at low wavenumber are assigned to $\mathrm{CH}$ stretching in the propyl groups. Both ILs exhibit bands at 2885 and $2943 \mathrm{~cm}^{-1}$, which can be assigned to $\mathrm{CH}$ vibrations in the propyl chain. ${ }^{40,41}$ Moreover, the spectra in this region exhibit a strong band at $2975 \mathrm{~cm}^{-1}$, which is again a contribution of the propyl chain. ${ }^{41}$ Concerning the bands above $3000 \mathrm{~cm}^{-1}$, all the spectroscopic literature mentioned that the vibrational bands at higher wavenumbers correspond to $\mathrm{C}(4 / 5)-\mathrm{H}$ stretching modes, whereas those at lower wavenumbers can be assigned to $\mathrm{C}(2)-\mathrm{H}$ stretching modes. ${ }^{40-42}$ In $\left[1-\mathrm{MPrIM}{ }^{+}\right]\left[\left(\mathrm{CF}_{3} \mathrm{SO}_{2}\right)_{2} \mathrm{~N}^{-}\right]$, absorption bands occur at 3103,3122 and $3157 \mathrm{~cm}^{-1}$, which can be attributed to the $\mathrm{C}(2)-\mathrm{H}$ and $\mathrm{H}-\mathrm{C}(4)$ $\mathrm{C}(5)-\mathrm{H}$ stretching vibration of the imidazolium ring respectively. ${ }^{40,41}$ On the contrary, in the methylated IL, $\left[1,2-\mathrm{DMPrIM}^{+}\right]\left[\left(\mathrm{CF}_{3} \mathrm{SO}_{2}\right)_{2} \mathrm{~N}^{-}\right]$, two important bands are observed at 3151 and $3188 \mathrm{~cm}^{-1}$ and they can be assigned to anti-symmetric and symmetric vibrations mode of $\mathrm{H}-\mathrm{C}(4)-\mathrm{C}(5)-\mathrm{H}$ stretching vibration.

In the case of non-methylated IL, [1-MPrIM $\left.{ }^{+}\right]$ $\left[\left(\mathrm{CF}_{3} \mathrm{SO}_{2}\right)_{2} \mathrm{~N}^{-}\right]$, three interaction positions are possible: $\mathrm{C}(2)-\mathrm{H}$ and $\mathrm{C}(4 / 5)-\mathrm{H}$. As reported by Fumino et al. ${ }^{23}$ when the $\mathrm{H}$ atom at $\mathrm{C}(2)$ is replaced by a $\mathrm{CH}_{3}$ group, the cation-anion interaction at this position is switched off. So, when we look in our spectra, 


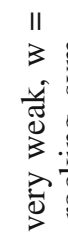

II

3

只象

กิ

क

约.

+

(1)

$\sum^{\circ}$

금

$\Xi$

ह

下

空

फิ

约

$\sum_{i=1}^{+}$

च

롱.

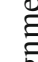

: 11

艺

है

宊

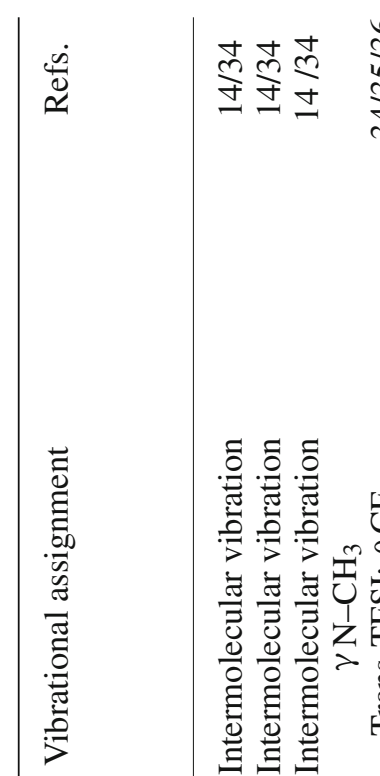

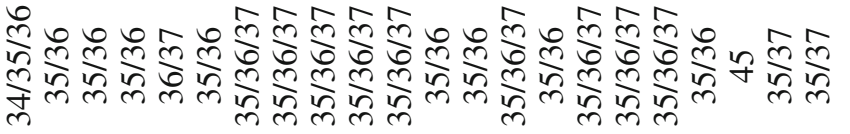

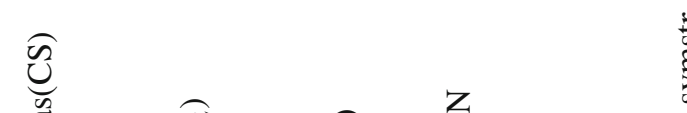

壱

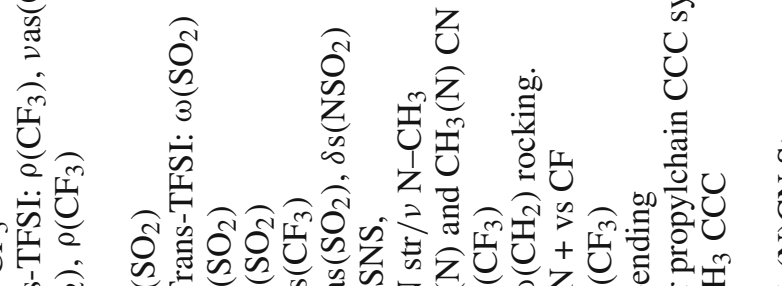

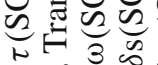

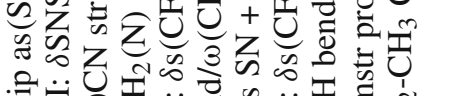

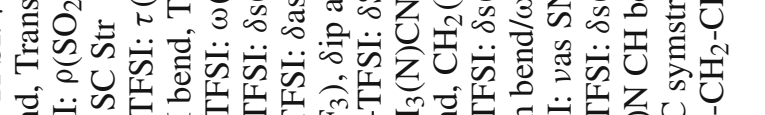

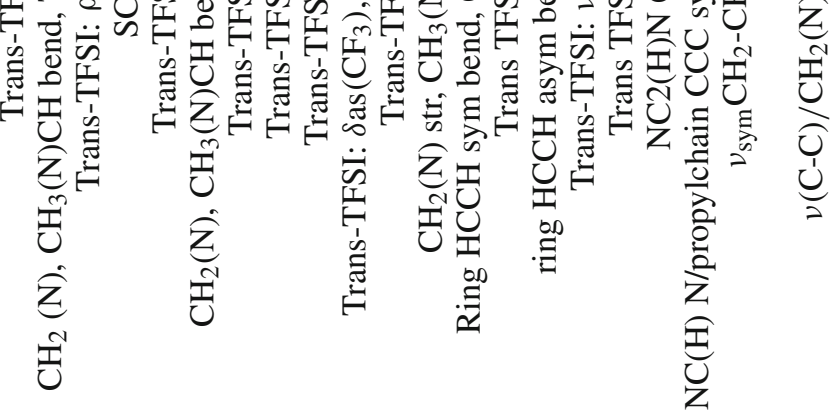

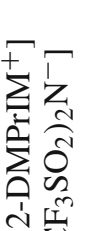

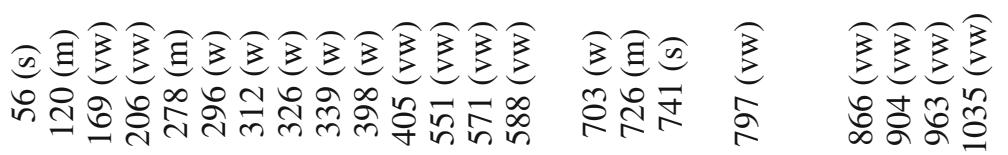

สี こْ

.

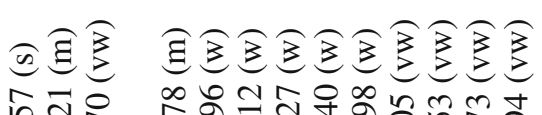

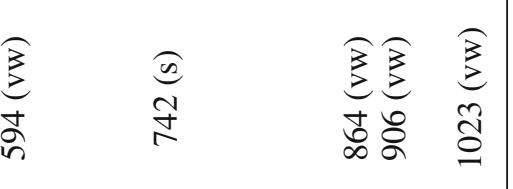

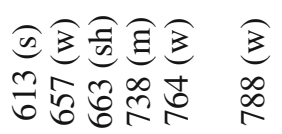

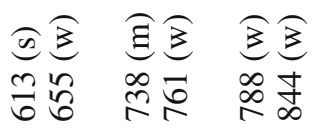




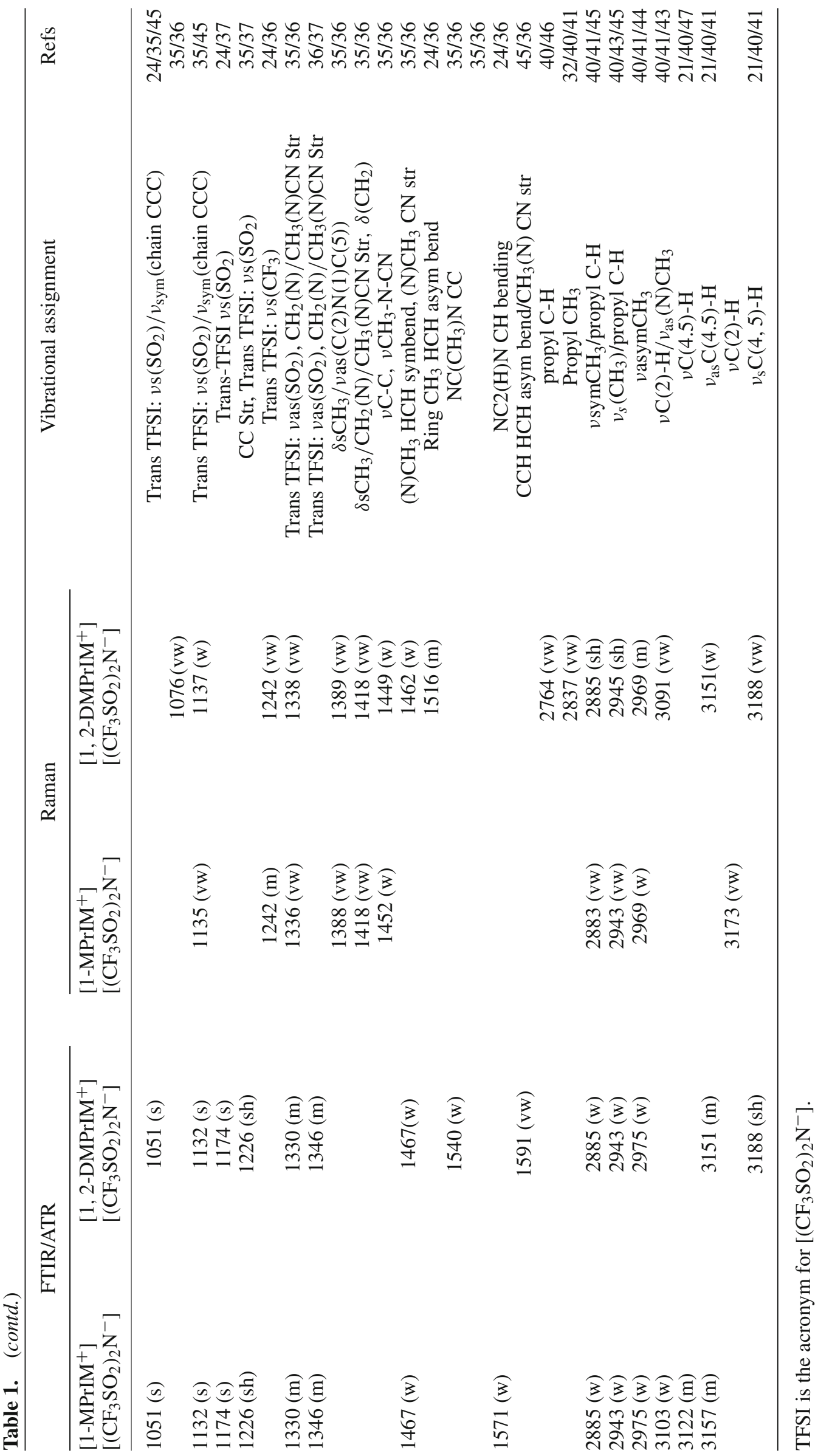




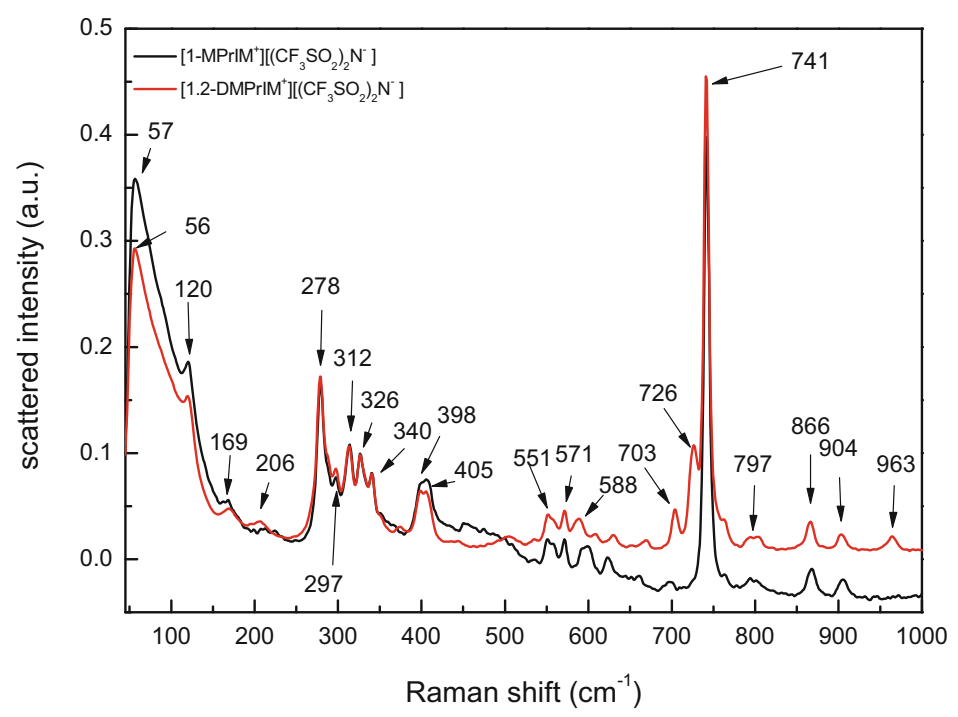

Figure 3. FT-RAMAN Spectra of $\left[1-\mathrm{MPrIM}^{+}\right]\left[\left(\mathrm{CF}_{3} \mathrm{SO}_{2}\right)_{2} \mathrm{~N}^{-}\right]$ and $\left[1,2-\mathrm{DMPrIM}^{+}\right]\left[\left(\mathrm{CF}_{3} \mathrm{SO}_{2}\right)_{2} \mathrm{~N}^{-}\right]$in the spectral range of $45-1000 \mathrm{~cm}^{-1}$.

the stretching modes between 3103 and $3122 \mathrm{~cm}^{-1}$ are completely missing in the FTIR/ATR spectra of methylated IL. For $\left[1-\mathrm{MPrIM}^{+}\right]\left[\left(\mathrm{CF}_{3} \mathrm{SO}_{2}\right)_{2} \mathrm{~N}^{-}\right] \mathrm{IL}$, the band at $3157 \mathrm{~cm}^{-1}$, is assigned to the $\mathrm{C}(4)-\mathrm{H} / \mathrm{C}(5)$ $\mathrm{H}$ symmetric stretching mode, while the same band in $\left[1,2-\mathrm{DMPrIM}^{+}\right]\left[\left(\mathrm{CF}_{3} \mathrm{SO}_{2}\right)_{2} \mathrm{~N}^{-}\right]$is blue shifted to a frequency of $3188 \mathrm{~cm}^{-1}$. This finding indicates that interaction cation-anion by $\mathrm{C}(4)-\mathrm{H} / \mathrm{C}(5)-\mathrm{H}$ position in methylated IL can take place only through these positions.

\subsection{FT-Raman spectroscopy}

The FT-RAMAN spectra $\left[45-3500 \mathrm{~cm}^{-1}\right]$ of $\left[1-\mathrm{MPrIM}^{+}\right]\left[\left(\mathrm{CF}_{3} \mathrm{SO}_{2}\right)_{2} \mathrm{~N}^{-}\right]$and $\left[1,2-\mathrm{DMPrIM}^{+}\right]$ $\left[\left(\mathrm{CF}_{3} \mathrm{SO}_{2}\right)_{2} \mathrm{~N}^{-}\right]$are illustrated in Figures $3,4,5$, and the observed FT-RAMAN bands and their assignment are listed in Table 1.

3.2a The 45-500 $\mathrm{cm}^{-1}$ region: In the range 45-200 $\mathrm{cm}^{-1}$, no significant difference between the two ILs were observed; three bands are seen for both ILs. These lines arise primarily from the intramolecular vibrations. These interactions are affected by the presence of $\left[\left(\mathrm{CF}_{3} \mathrm{SO}_{2}\right)_{2} \mathrm{~N}^{-}\right]$anion. ${ }^{34}$ The Raman modes at $56 \mathrm{~cm}^{-1}$ and $57 \mathrm{~cm}^{-1}$ are attributed to acoustic excitations, while the mode at $120 \mathrm{~cm}^{-1}$ is assigned to an intramolecular normal mode of $\left[\left(\mathrm{CF}_{3} \mathrm{SO}_{2}\right)_{2} \mathrm{~N}^{-}\right]$anion, and the mode at $204 \mathrm{~cm}^{-1}$ is related to vibrational motion of the imidazolium ring. ${ }^{34}$ In the second region between 500 and $1000 \mathrm{~cm}^{-1}$ (Figure 3), small differences around $700 \mathrm{~cm}^{-1}$ are observed between the spectra of the two
ILs, which will be further exploited in the subsequent Section 3.3.

$3.2 \mathrm{~b}$ The $1000-1700 \mathrm{~cm}^{-1}$ region: Concerning Raman spectra in $\left[1-\mathrm{MPrIM}^{+}\right]\left[\left(\mathrm{CF}_{3} \mathrm{SO}_{2}\right)_{2} \mathrm{~N}^{-}\right]$and $\left[1,2-\mathrm{DMPrIM}^{+}\right]\left[\left(\mathrm{CF}_{3} \mathrm{SO}_{2}\right)_{2} \mathrm{~N}^{-}\right]$, recent studies mentioned that the Raman bands at 278, 312, 326, 340, 398, 405, 551, 571, 588, 726, 741, 797, 866, 904, $1035,1137,1242$ and $1338 \mathrm{~cm}^{-1}$ can be assigned to the $\left[\left(\mathrm{CF}_{3} \mathrm{SO}_{2}\right)_{2} \mathrm{~N}^{-}\right]$anion, and these bands were also found in our measurements. ${ }^{34-36}$ Previous literature provided evidence that the bands at 278, 297, 312, and $398 \mathrm{~cm}^{-1}$ are due to both trans- and cis-conformer of $\left[\left(\mathrm{CF}_{3} \mathrm{SO}_{2}\right)_{2} \mathrm{~N}^{-}\right] ;{ }^{43,44}$ however, the band at $326 \mathrm{~cm}^{-1}$ was assigned to cis-conformer, while the line at $340 \mathrm{~cm}^{-1}$ can be associated only to trans- $\left[\left(\mathrm{CF}_{3} \mathrm{SO}_{2}\right)_{2} \mathrm{~N}^{-}\right]$. In our experimental spectra we observe the bands expected for both conformers of $\left[\left(\mathrm{CF}_{3} \mathrm{SO}_{2}\right)_{2} \mathrm{~N}^{-}\right]$. At higher Raman shift, both ILs display bands at 742 and $1242 \mathrm{~cm}^{-1}$, which according to the literature, ${ }^{42}$ are due to the symmetric $\mathrm{CF}_{3}$ stretching and deformation bands in the $\left[\left(\mathrm{CF}_{3} \mathrm{SO}_{2}\right)_{2} \mathrm{~N}^{-}\right]$anion.

As shown in Table 1 and Figure 4, the methylated IL $\left[1,2\right.$-DMPrIM $\left.{ }^{+}\right]\left[\left(\mathrm{CF}_{3} \mathrm{SO}_{2}\right)_{2} \mathrm{~N}^{-}\right]$, having an additional methyl group $\left(\mathrm{CH}_{3}\right.$ at $\mathrm{C}_{2}$ position), shows an intense band around $1516 \mathrm{~cm}^{-1}$, which is not observable in $\left[1-\mathrm{MPrIM}^{+}\right]\left[\left(\mathrm{CF}_{3} \mathrm{SO}_{2}\right)_{2} \mathrm{~N}^{-}\right]$; this band is probably assigned to $\mathrm{C} 2-\mathrm{CH}_{3}$ group, this group being absent in the non-methylated IL. ${ }^{24}$

$3.2 \mathrm{c}$ The $2700-3500 \mathrm{~cm}^{-1}$ region: Figure 5 shows high frequency Raman spectra of $\left[1-\mathrm{MPrIM}^{+}\right]$ 


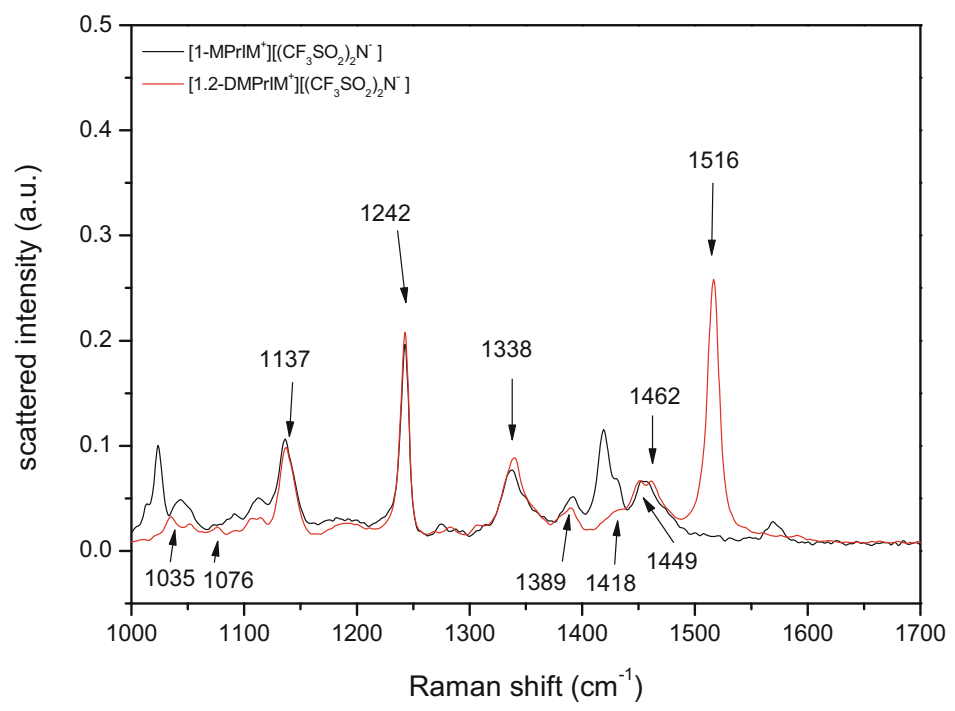

Figure 4. FT-RAMAN Spectra of $\left[1-\mathrm{MPrIM}^{+}\right]\left[\left(\mathrm{CF}_{3} \mathrm{SO}_{2}\right)_{2} \mathrm{~N}^{-}\right]$ and $\left[1,2-\mathrm{DMPrIM}^{+}\right]\left[\left(\mathrm{CF}_{3} \mathrm{SO}_{2}\right)_{2} \mathrm{~N}^{-}\right]$in the spectral range of $1000-1700 \mathrm{~cm}^{-1}$.

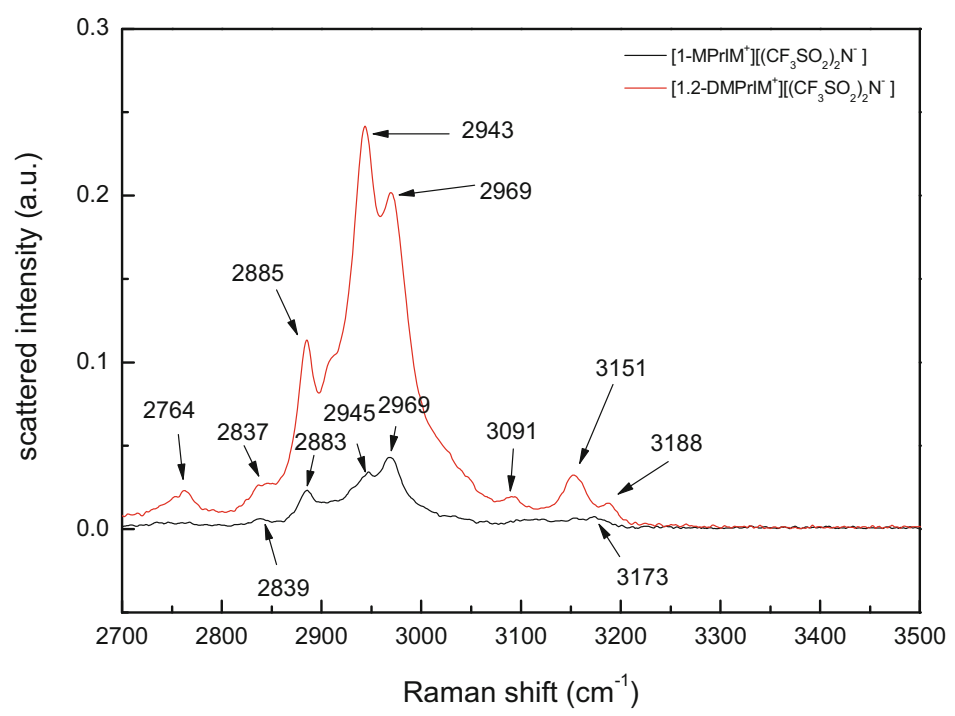

Figure 5. FT-RAMAN Spectra of $\left[1-\mathrm{MPrIM}^{+}\right]\left[\left(\mathrm{CF}_{3} \mathrm{SO}_{2}\right)_{2} \mathrm{~N}^{-}\right]$ and $\left[1,2-\mathrm{DMPrIM}^{+}\right]\left[\left(\mathrm{CF}_{3} \mathrm{SO}_{2}\right)_{2} \mathrm{~N}^{-}\right]$in the spectral range of $2700-3500 \mathrm{~cm}^{-1}$.

$\left[\left(\mathrm{CF}_{3} \mathrm{SO}_{2}\right)_{2} \mathrm{~N}^{-}\right]$and $\left[1,2-\mathrm{DMPrIM}^{+}\right]\left[\left(\mathrm{CF}_{3} \mathrm{SO}_{2}\right)_{2} \mathrm{~N}^{-}\right]$. in this region, we observe many differences in the vibrational spectra of the ILs. The Raman modes are located at 2839, 2883, 2945, $2969 \mathrm{~cm}^{-1}$ for [1-MPrIM ${ }^{+}$] $\left[\left(\mathrm{CF}_{3} \mathrm{SO}_{2}\right)_{2} \mathrm{~N}^{-}\right]$and at 2764, 2837, 2885, 2943, $2969 \mathrm{~cm}^{-1}$ for $\left[1,2-\mathrm{DMPrIM}^{+}\right]\left[\left(\mathrm{CF}_{3} \mathrm{SO}_{2}\right)_{2} \mathrm{~N}^{-}\right]$. All of them can be assigned to the $\mathrm{CH}$ stretching vibration of the $\left[1-\right.$ MPrIM $\left.^{+}\right]$and $\left[1,2-\right.$ DMPrIM $\left.^{+}\right]$chains. ${ }^{40}$ Furthermore, three bands are detected at 3091, 3151, $3188 \mathrm{~cm}^{-1}$ for $\left[1,2-\mathrm{DMPrIM}^{+}\right]\left[\left(\mathrm{CF}_{3} \mathrm{SO}_{2}\right)_{2} \mathrm{~N}^{-}\right]$, while only a very weak Raman band at $3173 \mathrm{~cm}^{-1}$ is observed for the non-methylated case. The first band at $3091 \mathrm{~cm}^{-1}$ originates from asymmetric stretch of $(\mathrm{N}) \mathrm{CH}_{3}$, while bands at $3151,3188 \mathrm{~cm}^{-1}$ are attributed to the antisymmetric and symmetric vibrations of $\mathrm{C}(4)-\mathrm{H} / \mathrm{C}(5)-$ $\mathrm{H}$, respectively. $\mathrm{C}(2)-\mathrm{H}$ vibration for non-methylated $\left[1-\mathrm{MPrIM}^{+}\right]\left[\left(\mathrm{CF}_{3} \mathrm{SO}_{2}\right)_{2} \mathrm{~N}^{-}\right]$is found at $3171 \mathrm{~cm}^{-1}$; this demonstrates that the interaction between $\left[\left(\mathrm{CF}_{3} \mathrm{SO}_{2}\right)_{2} \mathrm{~N}^{-}\right]$and the imidazolium ring is totally different in the two ILs. The fact that the Raman bands undergo a blue shift after methylation suggests that the hydrogen bonds through the $\mathrm{C}(4 / 5)-\mathrm{H}$ position are stronger in the methylated IL. 


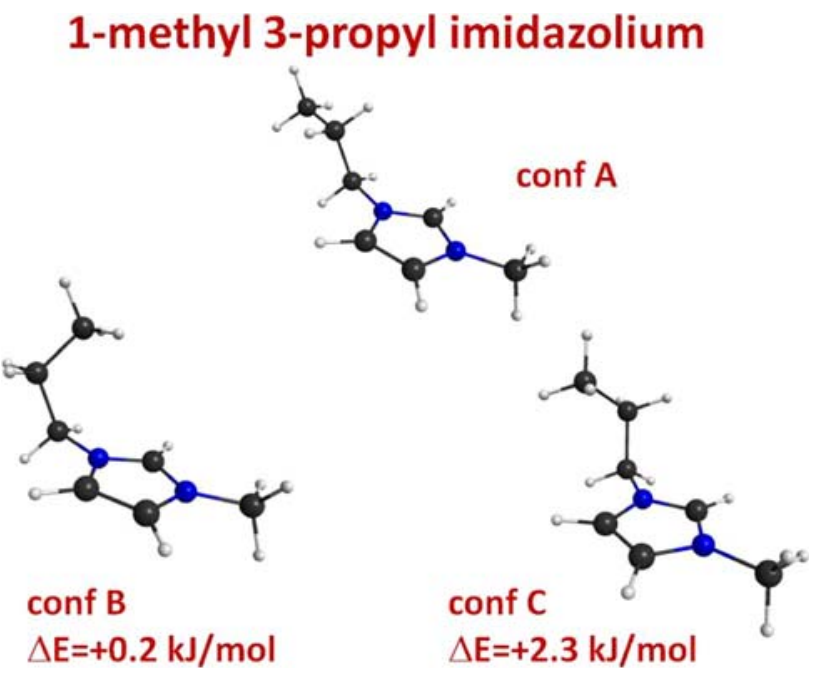

Figure 6. Schematic view of the three conformers of 1-methyl, 3-propyl imidazolium, with the relative energy difference with conformer A. Blue, black and light gray balls represent $\mathrm{N}, \mathrm{C}$ and $\mathrm{H}$ atoms, respectively.

\subsection{A study of the conformers of the imidazolium ions}

In this part, our discussion is focused on the comparison between the calculated Raman spectra of the conformers of both imidazolium cations and $\left(\mathrm{CF}_{3} \mathrm{SO}_{2}\right)_{2} \mathrm{~N}^{-}$anions and their presence in the experimental spectra of both ILs. The existence of two conformers of $\left(\mathrm{CF}_{3} \mathrm{SO}_{2}\right)_{2} \mathrm{~N}^{-}$ has been largely reported in the literature. ${ }^{37,38,43,44}$ Previous studies have shown that imidazolium ions can show the existence of conformers due to the flexibility of the alkyl chain attached to the ring. ${ }^{21,45}$ In the present study we investigated the possible existence of conformers by a systematic computational investigation of the two cations, using Spartan software for the computational study, ${ }^{48,49}$ which is able to perform a systematic variation of the angles between chemical bonds. A preliminary screening was performed at the molecular mechanics level and three possible geometries for each cation were found. Starting from these geometries, a minimization of the energy of each candidate was performed using the density functional theory.

Figures 6 and 7 present a schematic view of the three conformers of each cation, together with the energy difference $(\Delta E)$ with respect to the lowest energy one (conf. A). The atomic positions for all the conformers are reported in Tables S1-S6 in the Supporting Information. In the case of 1-methyl,3-propyl imidazolium, Conf. B and $\mathrm{C}$ show a $\Delta \mathrm{E}$ of +0.2 and $+2.3 \mathrm{~kJ} / \mathrm{mol}$, respectively. For 1,2-dimethyl,3-propyl imidazolium, both conf. B and $\mathrm{C}$ possess an energy $2.2 \mathrm{~kJ} / \mathrm{mol}$ higher than that of the lowest energy conformer (Conf. A). Even though Conf. B and C of 1,2-dimethyl,3-propyl imidazolium

\section{1, 2-dimethyl 3-propyl imidazolium}

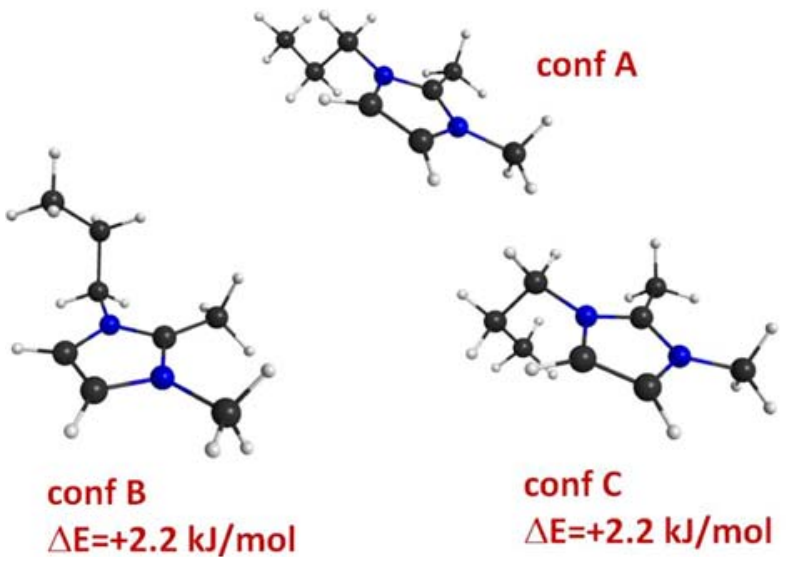

Figure 7. Schematic view of the three conformers of 1,2-dimethyl 3-propyl imidazolium, with the relative energy difference with conformer A. Blue, black and light gray balls represent $\mathrm{N}, \mathrm{C}$ and $\mathrm{H}$ atoms, respectively.

have the same energy difference with respect to Conf. $\mathrm{A}$, it must be kept in mind that they are different. One can note that for both cations, the energy difference between the conformers is extremely small, so that at room temperature all the conformational states can be populated with a non-negligible population. For example, with an energy difference of $2.2 \mathrm{~kJ} / \mathrm{mol}$, the higher energy state has a population of $30 \%$, while $70 \%$ of ions are in the lowest energy level.

In view of the fact that the calculations suggest that the energy difference between the conformers of the two imidazolium ions is extremely low, we checked whether any signature of the occurrence of more than one rotamer can be found in the vibrational spectra of the two ionic liquids. Therefore, we calculated the vibrational frequencies and their Raman intensity for the conformers of both 1-methyl,3-propyl imidazolium and 1,2-dimethyl,3-propyl imidazolium, using the B3LYP functional and the 6-31G** basis set. The list of the frequencies and Raman intensities is reported in Tables S7 and S8 in the Supporting Information. The Raman frequencies and intensities of the two conformers of $\left[\left(\mathrm{CF}_{3} \mathrm{SO}_{2}\right)_{2} \mathrm{~N}^{-}\right]$have been previously reported and a scaling factor of 1.04 for the calculated frequencies gave the best agreement with the position of the experimental bands. ${ }^{43,44}$ The Raman spectrum of each ion was simulated by summing Gaussian curves centered at each calculated vibration frequency with a fixed peak width of $10 \mathrm{~cm}^{-1}$.

Figures 8 and 9 present the comparison of the experimental Raman spectrum of the two ionic liquids with the Raman intensity calculated for each conformer of 


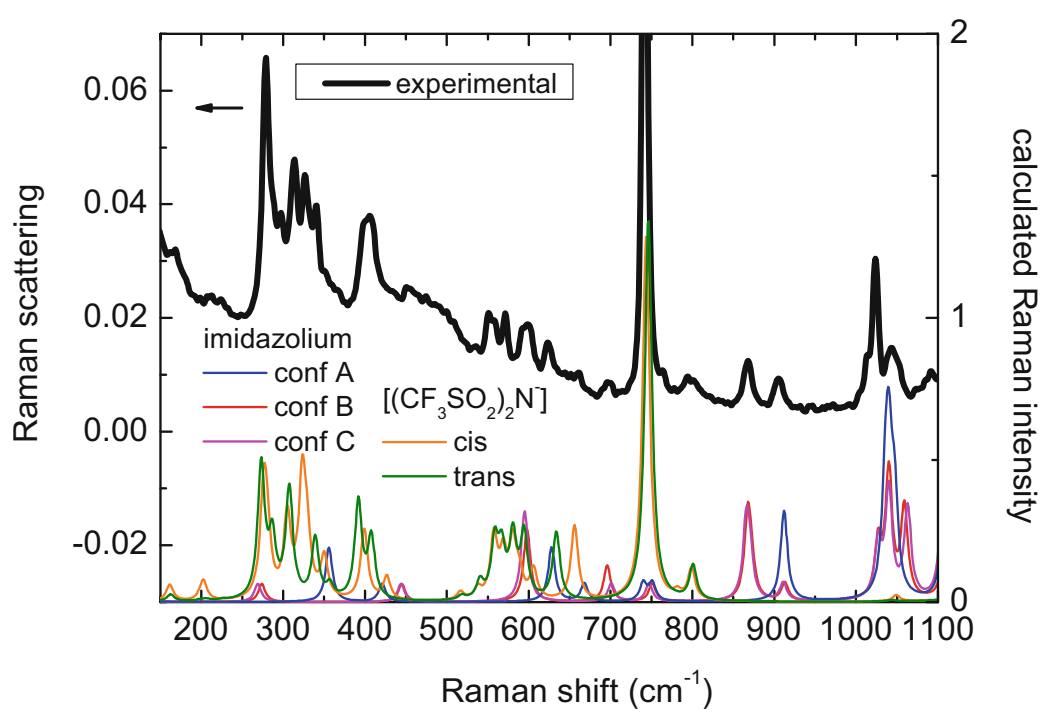

Figure 8. Experimental Raman spectrum of 1-methyl, 3-propyl imidazolium bis(trifluoromethane-sulfonyl) imide and calculated Raman intensity of the three conformers of 1-methyl 3-propyl imidazolium and of the two conformers of $\left[\left(\mathrm{CF}_{3} \mathrm{SO}_{2}\right)_{2} \mathrm{~N}^{-}\right]$. A scaling factor 1.04 is considered for $\left[\left(\mathrm{CF}_{3} \mathrm{SO}_{2}\right)_{2} \mathrm{~N}^{-}\right]$frequencies.

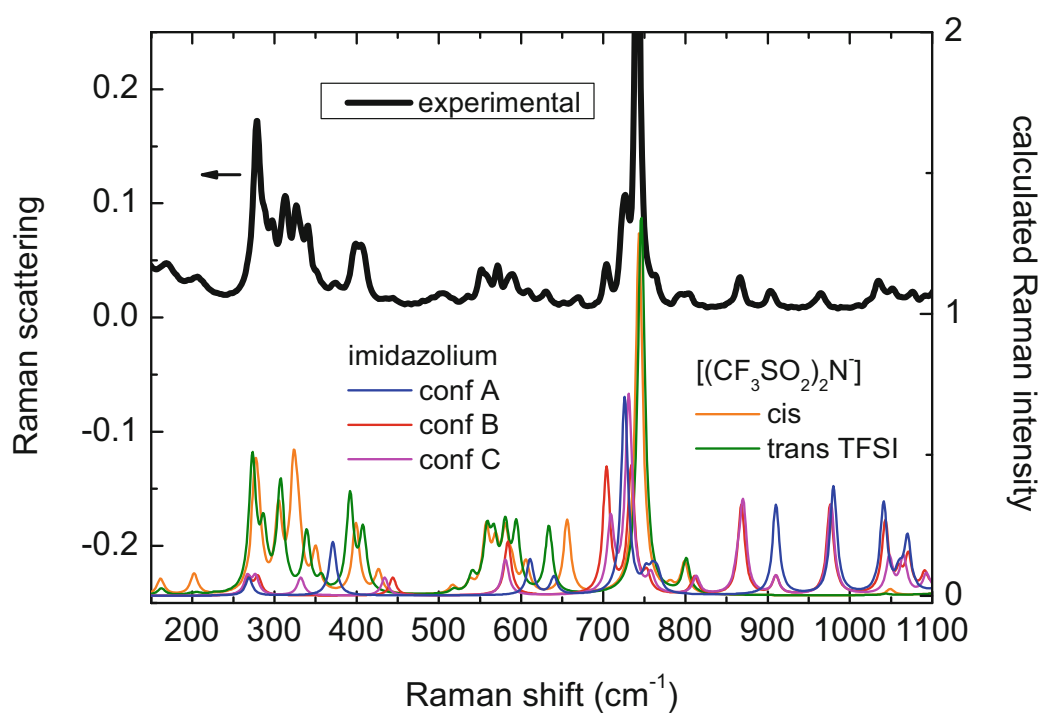

Figure 9. Experimental Raman spectrum of 1,2-dimethyl,3-propyl imidazolium bis(trifluoromethane-sulfonyl) imide and calculated Raman intensity of the three conformers of 1,2-dimethyl 3-propyl imidazolium and of the two conformers of $\left[\left(\mathrm{CF}_{3} \mathrm{SO}_{2}\right)_{2} \mathrm{~N}^{-}\right]$. A scaling factor 1.04 is considered for $\left[\left(\mathrm{CF}_{3} \mathrm{SO}_{2}\right)_{2} \mathrm{~N}^{-}\right]$frequencies.

the imidazolium ions and for the two conformers of $\left[\left(\mathrm{CF}_{3} \mathrm{SO}_{2}\right)_{2} \mathrm{~N}^{-}\right]$. Concerning 1-methyl,3-propyl imidazolium bis(trifluoromethane-sulfonyl) imide, one can note that Conf. $\mathrm{B}$ and $\mathrm{C}$ of the imidazolium ion give similar Raman spectra, which, however, are quite different from that of Conf. A (Figure 8). The line centered around $700 \mathrm{~cm}^{-1}$ is attributable to conformers B and C, while it is not present in the spectrum of conformer A.
The band around $867 \mathrm{~cm}^{-1}$ is expected for Conf. B and $\mathrm{C}$, but it should not occur in Conf. A. Finally, the line at $905 \mathrm{~cm}^{-1}$ should be present for all the three conformers, but it should have a much lower intensity in Conf. $\mathrm{B}$ and $\mathrm{C}$ than in Conf. A. Experimentally, the intensity of this line is comparable to that centered around 867 $\mathrm{cm}^{-1}$, suggesting the presence of a large concentration of Conf. A in the ionic liquid. 
The occurrence of more than one conformer is even more clear in 1,2-dimethyl,3-propyl imidazolium bis(trifluoromethane-sulfonyl) imide. In fact, it presents clear bands centered at 704 and $726 \mathrm{~cm}^{-1}$; the lower frequency band is attributable to Conf. B and $\mathrm{C}$, while the higher frequency band occurs in the calculated spectra of Conf. A and C. The experimental line centered around $374 \mathrm{~cm}^{-1}$ should be attributed to Conf. A. As for 1-methyl, 3-propyl imidazolium bis(trifluoromethanesulfonyl) imide, the band around $867 \mathrm{~cm}^{-1}$ is expected for Conf. B and C, but it should not occur in Conf. A. Moreover, the line at $903 \mathrm{~cm}^{-1}$ should be present for all the three conformers, but it should have a much lower intensity in Conf. B and C than in Conf. A. The comparable intensity of the line centered at 867 and $903 \mathrm{~cm}^{-1}$ indicates the presence of a large concentration of Conf. $\mathrm{A}$ in the ionic liquid.

In conclusion, the DFT calculations suggest that various conformers of the imidazolium ions are present in both ionic liquids.

\section{Conclusions}

In this work, two imidazolium ionic liquids having bis(trifluoromethane sulfonyl)imide anions, differing in the atoms attached to $\mathrm{C} 2$ positions, were successfully synthesized. The obtained ILs were identified by means of ${ }^{1} \mathrm{H},{ }^{13} \mathrm{C},{ }^{19} \mathrm{~F}-\mathrm{NMR}$ and FT-IR spectroscopy. The FTIR/ATR and Raman spectra of the synthesized ILs are reported. Also, Density Functional Theoretical study of the conformers of the imidazolium ions was performed at the B3LYP/6-31G** level. Experimentally, it was found that the methylation at the $\mathrm{C}(2)$ position can be demonstrated in the IR spectrum below $1700 \mathrm{~cm}^{-1}$ by the two bands centered at $844,1571 \mathrm{~cm}^{-1}$ and a single intense band centered at $1516 \mathrm{~cm}^{-1}$ in the Raman spectrum. Moreover, we observed a blue shift in the C4/C5-H stretching modes in the IR spectra, suggesting stronger interactions between the cation and anion through these positions in the case of methylated IL. Finally, the comparison between calculated and experimental Raman spectra suggests the existence of three conformers of the imidazolium cation in each IL. The most stable geometries of the conformers were obtained for both ILs.

\section{Supplementary Information (SI)}

All additional information pertaining to experimental data and characterization of the ionic liquids [1-MPrIM $\left.{ }^{+}\right]\left[\left(\mathrm{CF}_{3} \mathrm{SO}_{2}\right)_{2}\right.$ $\left.\mathrm{N}^{-}\right]$and $\left[1,2-\mathrm{DMPrIM}^{+}\right]\left[\left(\mathrm{CF}_{3} \mathrm{SO}_{2}\right)_{2} \mathrm{~N}^{-}\right]$using ${ }^{1} \mathrm{H},{ }^{13} \mathrm{C}$ and ${ }^{19} \mathrm{~F}-\mathrm{NMR}$ are given in Supplementary Information (Figures $\mathrm{S} 1$ and S2); the atomic positions for all the conformers are given in (Tables S1-S6); also, the list of the frequencies and Raman intensities (Tables S7 and S8) are given. Supporting Information is available at www.ias.ac.in/chemsci.

\section{Acknowledgements}

The authors gratefully acknowledge the financial support by MESRS, Univ-Saida, Algeria. H. B. also thanks Pr. Didier Villemin from LCMT-Caen for the helpful collaboration since 2008. We would like to thank Quentin Arnould, technician of Walloon Agricultural Research Centre (CRAW, Belgium), who participated in FT-Raman and FTIR/ATR measurements.

\section{References}

1. Lane G H 2012 Electrochemical reduction mechanisms and stabilities of some cation types used in ionic liquids and other organic salts Electrochim. Acta 83513

2. Chakrabarti M H, Mjalli F S, AlNashef I M, Hashim M A, Hussain M A, Bahadori L and Low C T J 2014 Prospects of applying ionic liquids and deep eutectic solvents for renewable energy storage by means of redox flow batteries Renewable Sustainable Energy Rev. 30254

3. Smith A M, Lovelock K R J, Gosvami N N, Licence P, Dolan A, Welton T and Perkin S 2013 Monolayer to bilayer structural transition in confined pyrrolidiniumbased ionic liquids J. Phys. Chem. Lett. 4378

4. Prechtl M 2016 In Nanocatalysis in Ionic Liquids (Germany: John Wiley)

5. Lei Z, Dai C and Chen B 2014 Gas solubility in ionic liquids Chem. Rev. 1141289

6. Palgunadi J and Sik K H 2010 The vibrational infrared spectra of 1-methyl-3-methylimidazolium dimethylphosphate. Is the dispersion-corrected functional important in intermolecular DFT calculation of ionic liquids? Spectrosc. Lett. 43513

7. Smiglak M, Pringle J M, Lu X, Han L, Zhang S, Gao H, MacFarlane D R and Rogers R D 2014 Ionic liquids for energy, materials, and medicine Chem. Commun. 50 9228

8. Singh M P, Singh R K and Chandra S 2014 Ionic liquids confined in porous matrices: Physicochemical properties and applications Prog. Mater. Sci. 6473

9. Geppert-Rybczyńska M, Lehmann J K and Heintz A 2014 Physicochemical properties of two 1-alkyl1-methylpyrrolidinium bis [(trifluoromethyl) sulfonyl] imide ionic liquids and of binary mixtures of 1-butyl1-methylpyrrolidinium bis [(trifluoromethyl) sulfonyl] imide with methanol or acetonitrile J. Chem. Thermodyn. 71171

10. Couadou E, Jacquemin J, Galiano H, Hardacre $\mathrm{C}$ and Anouti M 2013 A comparative study on the thermophysical properties for two bis [(trifluoromethyl) sulfonyl] imide-based ionic liquids containing the trimethylsulfonium or the trimethyl-ammonium cation in molecular solvents J. Phys. Chem. B 1171389

11. Neale A R, Li P, Jacquemin J, Goodrich P, Ball S C, Compton R G and Hardacre C 2016 Effect of cation structure on the oxygen solubility and diffusivity in a range of bis (trifluoromethyl) sulfonyl imide anion based 
ionic liquids for lithium-air battery electrolytes Phys. Chem. Chem. Phys. 1811251

12. Katsyuba S A, Vener M V, Zvereva E E, Fei Z, Scopelliti R, Laurenczy G, Yan N, Paunescu E and Dyson P J 2013 How strong is hydrogen bonding in ionic liquids? Combined X-ray crystallographic, infrared/Raman spectroscopic, and density functional theory study J. Phys. Chem. B 1179094

13. Roth C, Peppel T, Fumino K, Köckerling M and Ludwig R 2010 The importance of hydrogen bonds for the structure of ionic liquids: Single-crystal X-ray diffraction and transmission and attenuated total reflection spectroscopy in the terahertz region Angew. Chem. Int. Ed. 4910221

14. Penna T C, Faria L F O, Matos J R and Ribeiro M C C 2013 Pressure and temperature effects on intermolecular vibrational dynamics of ionic liquids J. Chem. Phys. 138 104503

15. Binetti E, Panniello A, Triggiani L, Tommasi R, Agostiano A, Curri M L and Striccoli M 2012 Spectroscopic study on imidazolium-based ionic liquids: Effect of alkyl chain length and anion J. Phys. Chem. B 1163512

16. Moumene T, Belarbi E H, Haddad B, Villemin D, Abbas O, Khelifa B and Bresson S 2014 Vibrational spectroscopic study of ionic liquids: Comparison between monocationic and dicationic imidazolium ionic liquids J. Mol. Struct. 1065-1066 86

17. Matthews R P, Welton T and Hunt P A 2015 Hydrogen bonding and $\pi-\pi$ interactions in imidazolium-chloride ionic liquid clusters Phys. Chem. Chem. Phys. 1714437

18. Clough M T, Geyer K, Hunt P A, McIntosh A J S, Rowe R, Welton T and White A J P 2016 Azoniaspiro salts: Towards bridging the gap between room-temperature ionic liquids and molten salts Phys. Chem. Chem. Phys. 183339

19. Bonhôte P, Dias A-P, Papageorgiou N, Kalyanasundaram K and Grätzel M 1996 Hydrophobic, highly conductive ambient-temperature molten salts Inorg. Chem. 351168

20. Hunt P A 2007 Why does a reduction in hydrogen bonding lead to an increase in viscosity for the 1-butyl-2, 3-dimethyl-imidazolium-based ionic liquids? J. Phys. Chem. B 1114844

21. Endo T, Kato T and Nishikawa K 2010 Effects of methylation at the 2 position of the cation ring on phase behaviors and conformational structures of imidazoliumbased ionic liquids J. Phys. Chem. B 1149201

22. Zhang Y and Maginn E J 2012 The effect of C2 substitution on melting point and liquid phase dynamics of imidazolium based-ionic liquids: Insights from molecular dynamics simulations Phys. Chem. Chem. Phys. 14 12157

23. Fumino K, Wulf A and Ludwig R 2008 Starke, lokalisierte und gerichtete H-Brücken machen ionische Flüssigkeiten beweglicher Angew. Chem. 1208859

24. Noack K, Schulz P S, Paape N, Kiefer J, Wasserscheid P and Leipertz A 2010 The role of the C2 position in interionic interactions of imidazolium based ionic liquids: A vibrational and NMR spectroscopic study Phys. Chem. Chem. Phys. 1214153

25. Izgorodina E I, Maganti R, Armel V, Dean P M, Pringle J M, Seddon K R and MacFarlane R 2011 Understanding the effect of the $\mathrm{C} 2$ proton in promoting low viscosities and high conductivities in imidazolium-based ionic liq- uids: part I. weakly coordinating anions J. Phys. Chem. B 11514688

26. Haddad B, Mokhtar D, Goussem M, Belarbi E H, Villemin D, Bresson S, Rahmouni M, Dhumal N R, Kim H J and Kiefer J 2017 Influence of methyl and propyl groups on the vibrational spectra of two imidazolium ionic liquids and their non-ionic precursors $J$. Mol. Struct. 1134582

27. Chen Z J and Lee J M 2014 Free volume model for the unexpected effect of C2-methylation on the properties of imidazolium ionic liquids J. Phys. Chem. B 1182712

28. Chen S, Vijayaraghavan R, MacFarlane D R and Izgorodina E I $2013 \mathrm{Ab}$ initio prediction of proton NMR chemical shifts in imidazolium ionic liquids J. Phys. Chem. B 1173186

29. Fumino K, Wulf A and Ludwig R 2009 The potential role of hydrogen bonding in aprotic and protic ionic liquids Phys. Chem. Chem. Phys. 118790

30. Lassègues J-C, Grondin J, Cavagnat D and Johansson P 2009 New interpretation of the $\mathrm{CH}$ stretching vibrations in imidazolium-based ionic liquids J. Phys. Chem. A 113 6419

31. Huang J-F, Chen P-Y, Sun I-W and Wang S P 2001 NMR Evidence of hydrogen bond in 1-ethyl-3methylimidazolium-tetrafluoroborate room temperature ionic liquid Spectrosc. Lett. 34591

32. Dong K, Zhang S, Wang D and Yao X 2006 Hydrogen bonds in imidazolium ionic liquids J. Phys. Chem. A 110 9775

33. Holbrey J D, Reichert W M and Rogers R D 2004 Crystal structures of imidazolium bis (trifluoromethanesulfonyl) imide 'ionic liquid'salts: The first organic salt with a cisTFSI anion conformation Dalton Trans. 20042267

34. Moumene T, Belarbi E H, Haddad B, Villemin D, Abbas O, Khelifa B and Bresson S 2015 Study of imidazolium dicationic ionic liquids by Raman and FTIR spectroscopies: The effect of the nature of the anion J. Mol. Struct. 1083179

35. Moschovi A M, Ntais S, Dracopoulos V and Nikolakis V 2012 Vibrational spectroscopic study of the protic ionic liquid 1-H-3-methylimidazolium bis (trifluoromethanesulfonyl) imide Vib. Spec. 63350

36. Fujii K, Fujimori T, Takamuku T, Kanzaki R, Umebayashi Y and Ishiguro S 2006 Conformational equilibrium of bis (trifluoromethanesulfonyl) imide anion of a room-temperature ionic liquid: Raman spectroscopic study and DFT calculations J. Phys. Chem. B 1108179

37. Lassègues $\mathrm{J} \mathrm{C}$, Grondin $\mathrm{J}$, Holomb $\mathrm{R}$ and Johansson $\mathrm{P}$ 2007 Raman and ab initio study of the conformational isomerism in the 1-ethyl-3-methyl-imidazolium bis (trifluoromethanesulfonyl) imide ionic liquid J. Raman Spectrosc. 38551

38. Capitani F, Gatto S, Postorino P, Palumbo O, Trequattrini F, Deutsch M, Brubach J-B, Roy P and Paolone A 2016 The complex dance of the two conformers of bis (trifluoromethanesulfonyl) imide as a function of pressure and temperature J. Phys. Chem. B 1201312

39. Roth C, Chatzipapadopoulos S, Kerlé D, Friedriszik F, Lütgens M, Lochbrunner S, Kühn and Ludwig R 2012 Hydrogen bonding in ionic liquids probed by linear and nonlinear vibrational spectroscopy New J. Phys. 14 105026 
40. Cha S, Ao M, Sung W, Moon B, Ahlström B, Johansson P, Ouchi Y and Kim D 2014 Structures of ionic liquid-water mixtures investigated by IR and NMR spectroscopy Phys. Chem. Chem. Phys.16 9591

41. Jeon Y, Sung J, Seo C, Lim H, Cheong H, Kang M, Moon B, Ouchi Y and Kim D 2008 Structures of ionic liquids with different anions studied by infrared vibration spectroscopy J. Phys. Chem. B 1124735

42. Berg R W 2007 Raman spectroscopy and ab-initio model calculations on ionic liquids Monatsch. Chem. 1381045

43. Capitani F, Trequattrini F, Palumbo O, Paolone A and Postorino P 2016 Phase transitions of PYR 14 -TFSI as a function of pressure and temperature: the competition between smaller volume and lower energy conformer $J$. Phys. Chem. B 1202921

44. Herstedt M, Smirnov M, Johansson P, Chami M, Grondin J, Servant L and Lassègues J C 2005 Spectroscopic characterization of the conformational states of the bis (trifluoromethanesulfonyl) imide anion (TFSI-) $J$. Raman Spectrosc. 36762

45. Holomb R, Martinelli A, Albinsson I, Lassègues J C, Johansson P and Jacobsson P 2008 Ionic liquid structure: the conformational isomerism in 1-butyl-3methyl-imidazolium tetrafluoroborate ([bmim][BF4]). J. Raman Spectrosc. 39793.

46. Heimer N E, Del Sesto R E, Meng Z, Wilkes J S and Carper W R 2006 Vibrational spectra of imidazolium tetrafluoroborate ionic liquids. J. Mol. Liq. 12484
47. Chang H-C, Jiang J-C, Su J-C, Chang C-Y and Lin S H 2007 Evidence of rotational isomerism in 1-butyl-3methylimidazolium halides: A combined high-pressure infrared and Raman spectroscopic study J. Phys. Chem. A 1119201

48. Shao Y, Molnar L F, Jung Y, Kussmann J, Ochsenfeld C, Brown S T, Gilbert A T B, Slipchenko L V, Levchenko S V, O'Neill D P, DiStasio R A Jr., Lochan R C, Wang T, Beran G J O, Besley N A, Herbert J M, Lin C Y, Van Voorhis T, Chien S H, Sodt A, Steele R P, Rassolov V A, Maslen P E, Korambath P P, Adamson R D, Austin B, Baker J, Byrd E F C, Dachsel H, Doerksen R J, Dreuw A, Dunietz B D, Dutoi A D, Furlani T R, Gwaltney S R, Heyden A, Hirata S, Hsu C-P, Kedziora G, Khalliulin R Z, Klunzinger P, Lee A M, Lee M S, Liang W Z, Lotan I, Nair N, Peters B, Proynov E I, Pieniazek P A, Rhee Y M, Ritchie J, Rosta E, Sherrill C D, Simmonett A C, Subotnik J E, Woodcock H L III, Zhang W, Bell A T, Chakraborty A K, Chipman D M, Keil F J, Warshel A, Hehre W J, Schaefer H F, Kong J, Krylov A I, Gill P M W and Head-Gordon M 2006 Advances in methods and algorithms in a modern quantum chemistry program package Phys. Chem. Chem. Phys. 83172

49. Hehre W J 2003 In A guide to molecular mechanics and quantum chemical calculations (Irvine, CA: Wavefunction Inc.) 